\title{
Content Validity of the Comprehensive ICF Core Set for Chronic Obstructive Pulmonary Diseases: An International Delphi Survey
}

\author{
Andrea Jobst ${ }^{1,2}$, Inge Kirchberger ${ }^{*}, 1,2$, Alarcos Cieza ${ }^{1,2,3,4}$, Gerold Stucki ${ }^{2,4,5}$ and \\ Armin Stucki ${ }^{6,7}$
}

\author{
${ }^{1}$ Institute for Health and Rehabilitation Sciences (IHRS), Ludwig Maximilians Universität, Munich, Germany \\ ${ }^{2}$ ICF Research Branch, WHO FIC CC Germany (DIMDI) at SPF, Nottwil, Switzerland and at IHRS, Ludwig \\ Maximilians Universität, Munich, Germany \\ ${ }^{3}$ Faculty of Social and Human Sciences, School of Psychology, University of Southampton, Southampton, UK \\ ${ }^{4}$ Swiss Paraplegic Research, Nottwil, Switzerland \\ ${ }^{5}$ Department of Health Sciences and Health Policy, University of Lucerne and SPF, Nottwil, Switzerland \\ ${ }^{6}$ Clinic and Policlinic for Pulmology, Inselspital, University Hospital Berne, Switzerland \\ ${ }^{7}$ Berner Rehabilitation Center Heiligenschwendi, Switzerland
}

\begin{abstract}
Introduction: The "Comprehensive ICF Core Set for Chronic Obstructive Pulmonary Diseases (COPD)" is an application of the International Classification of Functioning, Disability and Health (ICF) and represents the typical spectrum of problems in functioning of patients with COPD. The objective of this study was to validate this ICF Core Set from the perspective of physicians.
\end{abstract}

Materials and Methodology: Physicians experienced in COPD treatment were asked about the patients' problems treated by physicians in patients with COPD in a three-round electronic mail survey using the Delphi technique. Responses were linked to the ICF.

Results: Seventy-six physicians in 44 countries gave a total of 1330 responses that were linked to 148 different ICF categories. Nine ICF categories were not represented in the Comprehensive ICF Core Set for COPD although at least $75 \%$ of the participants have rated them as important. Nineteen concepts were linked to the not yet developed ICF component personal factors and seventeen concepts were not covered by the ICF.

Conclusion: The high percentage of ICF categories represented in the ICF Core Set for COPD indicates satisfactory content validity from the perspective of the physicians. However, some issues were raised that were not covered and need to be investigated further.

Keywords: Chronic obstructive pulmonary disease, asthma, rehabilitation, international classification of functioning, disability and health, ICF core set.

\section{INTRODUCTION}

Chronic obstructive pulmonary diseases (COPD), as defined by the Global Initiative for Chronic Obstructive Lung Disease (GOLD), are characterized by airflow obstruction that is no longer fully reversible and is usually progressive. [1-3]. COPD often leads to limitations of physical activities and restrictions in daily activities and societal participation [4,5]. Furthermore, psychological problems like anxiety and depression are common [6].

*Address correspondence to this author at the Department of Medical Informatics, Biometry and Epidemiology, Chair for Public Health and Health Care Research, Unit for Biopsychosocial Health, LudwigMaximilians Universität, Munich, Germany;

Tel: ++49-89-2180-78216; Fax: ++49-89-2180-78230;

E-mail: Inge.Kirchberger@med.uni-muenchen.de
To optimize interventions aimed at maintaining functioning and minimizing disability, a proper understanding of these limitations of the patients' functioning is needed [7]. The World Health Organization International Classification of Functioning, Disability and Health (ICF) offers a useful framework for classifying the components of health and consequences of a disease. It aims at providing a unified language for the description of health conditions in rehabilitation and a common framework for all health professions [8]. According to the ICF, the problems associated with a disease may concern body functions and structures, the performance of activities and participation in life situations. Health states and the development of disability are modified by contextual factors such as environmental and personal factors [8]. 


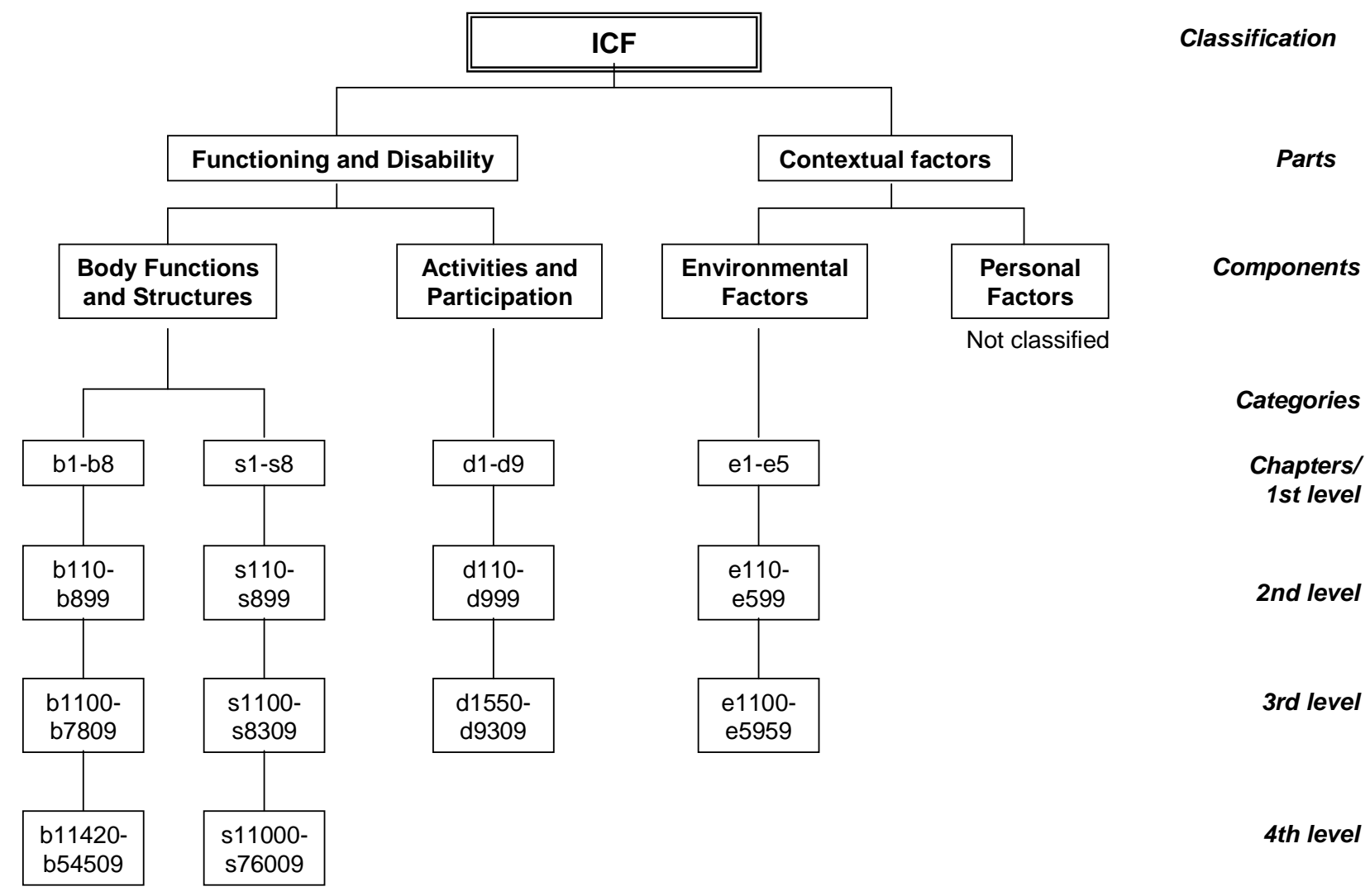

Fig. (1). Structure of the International Classification of Functioning, Disability and Health (with permission of the World Health Organization (WHO). All rights are reserved by the WHO)

The ICF is structured into two parts - Functioning \& Disability (Part 1) and Contextual Factors (Part 2). The overall structure of the ICF is shown in Fig. (1). Part 1 covers functioning and disability and includes the components: Body Functions (b), Body Structures (s) and Activities and Participation (d). In contrast to other disability models, the ICF classifies contextual factors (Part 2) that may either facilitate or hinder functioning and therefore affect the development of disability. These contextual factors consist of two components. The component Environmental Factors (e) encompasses categories of the physical, social or attitudinal world. The second component is Personal Factors (pf) that include gender, age, habits, lifestyle, coping style, etc. 'Personal factors' are not yet contained in the current ICF version.

Categories are the units of the ICF classification. They are arranged in a stem-branch-leaf scheme, so that a lowerlevel category shares the attributes of the higher level of which it is a member. For further information on the conceptual background, underlying definitions and structure of the ICF, we refer to the respective WHO publication [8].

Despite its supposed value, the ICF as a whole including more than 1400 categories - is not feasible for use in clinical practice. In order to facilitate the implementation of the ICF into clinical practice, ICF Core Sets for a number of health conditions including COPD [9], have been developed [10]. The Comprehensive ICF Core Set for COPD includes a set of categories out of the whole ICF, which covers the typical spectrum of problems in functioning in patients with COPD [9]. It was developed in a formal decision-making and consensus process integrating evidence gathered from preliminary studies and expert knowledge [11-13].

While the GOLD definition of COPD does not specifically include patients with chronic bronchitis and emphysema, it is clear that they are considered to be the predominant causes of COPD.

The inclusion of patients with asthma in the ICF Core Sets for COPD was a major challenge at the beginning of the development process [8]. COPD and asthma differ with regard to age, risk factors, course and treatment. However, many symptoms presented by patients do not clearly relate exclusively to either asthma or COPD, and the distinction between these conditions may become quite difficult, especially when COPD is complicated by acute viral or irritant-induced bronchospasm, for example. Therefore it was clearly decided to include asthma under the umbrella term COPD by keeping in mind the need to focus on patients in more severe stages with some degree of fixed airflow obstruction.

Otherwise less common forms of chronic obstructive lung disorders with vastly different etiologies, pathogenesis, symptoms and outcomes, e.g. bronchiectasis, upper-airway 
lesions, bronchiolar diseases and some interstitial lung diseases, were excluded [9].

The Comprehensive ICF Core Set for COPD is now undergoing worldwide testing and validation using a number of approaches including international multi-centre field studies and validation from the patients' perspective. One key aspect is the validation from the user perspective. Since ICF Core Sets should serve as a standard for multiprofessional assessment and assessment in clinical trials, it is most important whether the categories included in the Comprehensive ICF Core Sets cover the patients' problems addressed by the specific interventions of health professionals.

Therefore, the objective of this study was to validate the Comprehensive ICF Core Set for COPD from the perspective of physicians. The specific aims were firstly, to identify the patients' problems, resources and aspects of environment treated by physicians in patients with COPD and secondly, to examine how these aspects are represented by the current version of the Comprehensive ICF Core Sets for COPD.

\section{MATERIALS AND METHODOLOGY}

We conducted a three-round electronic-mail survey of physicians using the Delphi technique [14]. The Delphi method is a structured communication technique which aims to gain consensus from a panel of individuals who have knowledge of the topic being investigated [15]. These informed persons are commonly titled as 'experts'. The experts are requested to complete questionnaires in two or more rounds. Typically, the first round is used to generate ideas and starts with an open question thus allowing participants freedom in their responses. In each of the following rounds, a summary of the previous round is included and evaluated by the participants. The participants are enabled to compare the group results with their own response and are encouraged to revise their answers in light of the replies of other participants. During this process the range of answers is expected to decrease and the group will converge towards a "consensus". The Delphi process is stopped after a pre-defined criterion (e.g. number of rounds). Besides structured information flow and regular feedback, anonymity of the participants is another key characteristic of the Delphi methods [16]. It provides an equal chance for each participant to present ideas unbiased by other participants. Since the Delphi technique is based on written information and does not require the physical presence of the participants, the method facilitates international, email- or internet-based execution of studies.

\section{Recruitment of Participants}

In the preparatory phase of the study, 25 associations for respiratory medicine found by internet search were contacted by e-mail. In addition, literature search and personal recommendations were used to identify experts. Accessorily, a register of members of a German pulmonary specialist association was used to get in contact with German experts. The sample was selected using a purposive sampling approach. Purposive sampling is based on the assumptions that a researcher's knowledge about the population can be used to handpick the cases to be included in the sample [17].
Lacking a world-wide accepted definition of an 'expert in respiratory medicine', the initial letter notes that participants should be "physicians experienced in the treatment of COPD”.

The first contact included an invitation to cooperate and a detailed description of the projects targets, the Delphi process and the timeline. Only persons who agreed to participate were included into the expert sample and received the questionnaire of the first Delphi round.

\section{Delphi Process}

The process and verbatim questions of the electronicmail survey using the Delphi technique are displayed in Fig. (2). The participants had 3 weeks to mail their responses for each round. Reminders were sent one week and 2 days before deadline.

In round 1 of the Delphi survey an information letter including instructions and an Excel file containing an openended questionnaire was sent to all experts. In the questionnaire the participants were requested to list all the patients' problems, patients' resources and aspects of environment treated by physicians in patients with COPD. Additionally, the participants were asked to complete questions on demographic characteristics and professional experience. Responses were collected and linked to the ICF.

In the second Delphi round, the participants received a list of the ICF categories linked to the responses of the first round. The responses that could not be linked to an existing ICF category were categorized by the research team and listed. The participants were requested to agree or disagree whether the respective ICF category represents patients' problems, patients' resources or aspects of environment treated by physicians in patients with COPD.

In the third Delphi round the participants received a list of the ICF categories including the proportion and the identification numbers of the participants who did agree that the categories represent patients' problems, patients' resources or aspects of environment treated by physicians in patients with COPD. The participants were requested to answer the same question taking into account the responses of the group as well as their previous response.

\section{Linking}

An ICF category is coded by the component letter and a suffix of one to five digits. The letters $b, s, d$ and e refer to the components Body Functions (b), Body Structures (s), Activities and Participation (d) and Environmental Factors (e) (Fig. 1). This letter is followed by a one digit number indicating the chapter, the code for the second level (two digits) and the third and fourth levels (one digit each). A higher-level (more detailed) category shares the lower-level categories of which it is the member, i.e. the use of a higherlevel category implies that the lower-level category is applicable, but not the other way round.

Each response of the first Delphi round was linked to the most precise ICF category. The linkage was performed separately by two health professionals on the basis of ten linking rules, established in previous studies [18]. 


\section{Question:}

Round 1 What are the patients' problems, patients' resources and aspects of environment treated by physicians in patients with COPD?

\section{Question:}

Do you agree that this ICF category represents

Round 2 patients' problems, patients' resources or aspects of the environment treated by physicians in patients with COPD?

\section{Question:}

Taking into account the answer of the group and your individual answer in the second round, do you agree that this ICF category represents patients' problems, patients' resources or aspects of the environment treated by physicians in patients with COPD?

Fig. (2). Description of the Delphi process.

\section{Statistical Methods}

Statistical analysis was performed using SAS for windows Version 8. Descriptive statistics were used to characterize the sample and frequencies of responses. Kappa statistics with bootstrapped confidence intervals were used to describe the agreement between the two health professionals who performed the linking $[19,20]$.

\section{RESULTS}

\section{Recruitment and Participants}

Three hundred thirty seven physicians found by internet search were contacted and 54 of them participated in the first Delphi round. Of the German Association for Pneumology and Respiratory Medicine, 109 members were invited to participate, 15 agreed and eight participated in the first round of the study. By literature search, 12 additional experts were contacted and participated in the study. On the basis of personal recommendations of other participants ("snowball system") 14 persons were contacted. Two of them participated in the first round of the Delphi process.

Seventy-six of 99 physicians $(76.8 \%)$ who agreed to participate in the study filled in the first round questionnaire. The demographic and professional characteristics of the experts are shown in Table $\mathbf{1 .}$

\section{Delphi Process}

In the first Delphi round, 1330 patients' problems, patients' resources or aspects of environment treated by physicians in patients with COPD were named. Sixty-five of 76 participants $(85.5 \%)$ returned the second round questionnaire. The third round questionnaire was completed by 61 of $65(93.8 \%)$ participants.

\section{Linking Process}

A total of 148 ICF categories were linked to the pulmologists' responses. Health conditions such as 'pneumonia' and 'respiratory infection' that were used in many responses as e.g. a substitute or umbrella term for the underlying disease or as an independent risk factor, were assigned Health conditions. Health conditions are classified and coded in the complementary International Classification of Diseases, ICD 10 [21]. The content of the identified 19 responses linked to the ICF component Personal factors, refers to coping strategies, personal wishes, helplessness and dependencies. Seventeen responses were found not to be covered by the ICF, such as oedema, exacerbations and prevention of exacerbations, expectorations, carbon dioxide retention and lung function studies.

The Kappa statistic for the linking was 0.66 with a $95 \%$ bootstrapped confidence interval of $0.63-0.69$.

\section{Representation of the Physicians' Responses in the Comprehensive ICF Core Set for COPD}

All components of the ICF were represented in the participants' responses. Tables 2-5 show the linking of the experts' responses to the ICF categories of the four ICF components Body Functions (Table 2), Body Structures (Table 3), Activities and Participation (Table 4) and Environmental Factors (Table 5).

Of the 148 identified ICF categories, nine are not represented in the Comprehensive ICF Core Set for COPD and considered important by at least $75 \%$ of the participants (see Tables 2-5). Eight of these ICF categories belong to the ICF component Body Functions (Table 2). 
Table 1. Attrition of Participants Between the Delphi Rounds, Demographics and Professional Experience of the Round 1 Participants

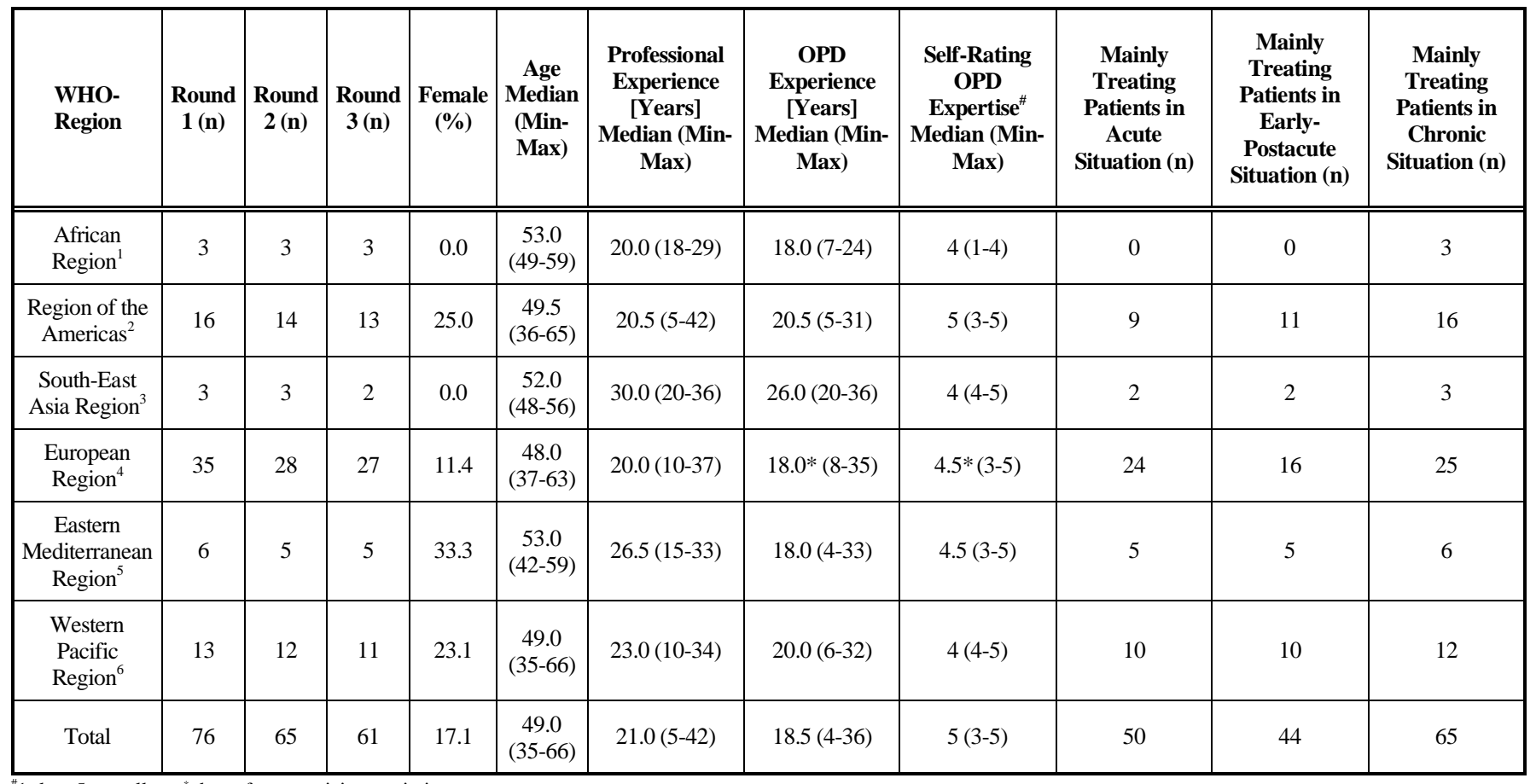

${ }^{\#} 1=$ low 5=excellent; ${ }^{*}$ data of one participant missing

${ }^{1}$ Cameroon, Nigeria, South Africa, Sudan

${ }^{2}$ Argentina, Canada, Mexico, Peru, Trinidad and Tobago, United States of America, Uruguay

${ }^{3}$ India, Republic of Korea, Thailand

${ }^{4}$ Austria, Bulgaria, Croatia, Finland, France, Germany, Hungary, Iceland, Italy, Kyrgyzstan, Malta, Norway, Portugal, Russia, Serbia and Montenegro, Slovenia, Switzerland, Turkey

${ }^{5}$ Egypt, Iran, Lebanon, Syria, Tunisia,

${ }^{6}$ Australia, Hong Kong China, Japan, Malaysia, New Zealand, Philippines, Vietnam.

\section{DISCUSSION}

This paper recruited physicians experienced in the treatment of COPD by contacting national and international associations for respiratory medicine, conducted a threeround electronic-mail survey of physicians using the Delphi technique, examined the content by linking the concepts to the ICF and generated an inventory which shows the extent to which the patients' problems, resources and environmental factors treated by physicians are represented in the Comprehensive ICF Core Set for COPD. Lacking a universal definition of an appropriate level of consensus and based on previous studies, an agreement of at least $75 \%$ among the physicians in the final Delphi round was considered sufficiently high [10, 22]. Consequently, ICF categories with an agreement of at least $75 \%$, which are not represented in the Comprehensive ICF Core Set for COPD may indicate missing content validity from the perspective of physicians.

By linking all responses it could be shown that the Comprehensive ICF Core Set for COPD is a valid tool with few exceptions. A total of 148 categories were used to map the contents of the pulmologists' responses. The finding that the content of only nine categories is not covered by the current Comprehensive ICF Core Set for COPD supports its comprehensiveness and content validity.

However, it is interesting to note that eight of these nine ICF categories cover contents within the component Body
Functions. Considering Body Functions are the key focus of most physicians acting in respiratory medicine, this is not surprising.

Most participants agreed that the ICF category $b 110$ Consciousness functions represents a problem in patients with COPD. Patients with advanced COPD are prone to acute and or chronic respiratory failure, resulting in hospital admission. Clinically, an impairment of the lung as gas exchanger often results in an altered level of consciousness, being a key factor for initiating and maintaining a noninvasive positive pressure ventilation (NPPV) [23]. Thus, from the perspective of physicians, an inclusion of this category in the Comprehensive ICF Core Set for COPD is most important.

The categories b1263 Psychic stability and b1265 Optimism are not included in the Comprehensive ICF Core Set for COPD, but were considered important by the participants. Emotional disorders including depressive symptoms and episodes as well as fears have been found to be very common $[6,24,25]$. Therefore, depression and anxiety are key treatment targets e.g. in pulmonary rehabilitation settings. However, these problems are already sufficiently represented in the Comprehensive ICF Core Set for COPD by the ICF category b152 Emotional functions.

Many participants agreed on the ICF categories b420 Blood vessel functions and b415 Blood pressure functions with respect to pulmonary arterial hypertension (PAH). 
Table 2. Linking of the Experts Responses to the ICF Categories of the Component Body Functions: The Table Denotes the Percentage of Experts who Considered the Respective ICF Category as Relevant in the Third Delphi Round and the Correlation with the Comprehensive ICF Core Set for COPD. ICF Categories Included Comprehensive ICF Core Set for COPD are Printed in the Bold-Face Type.

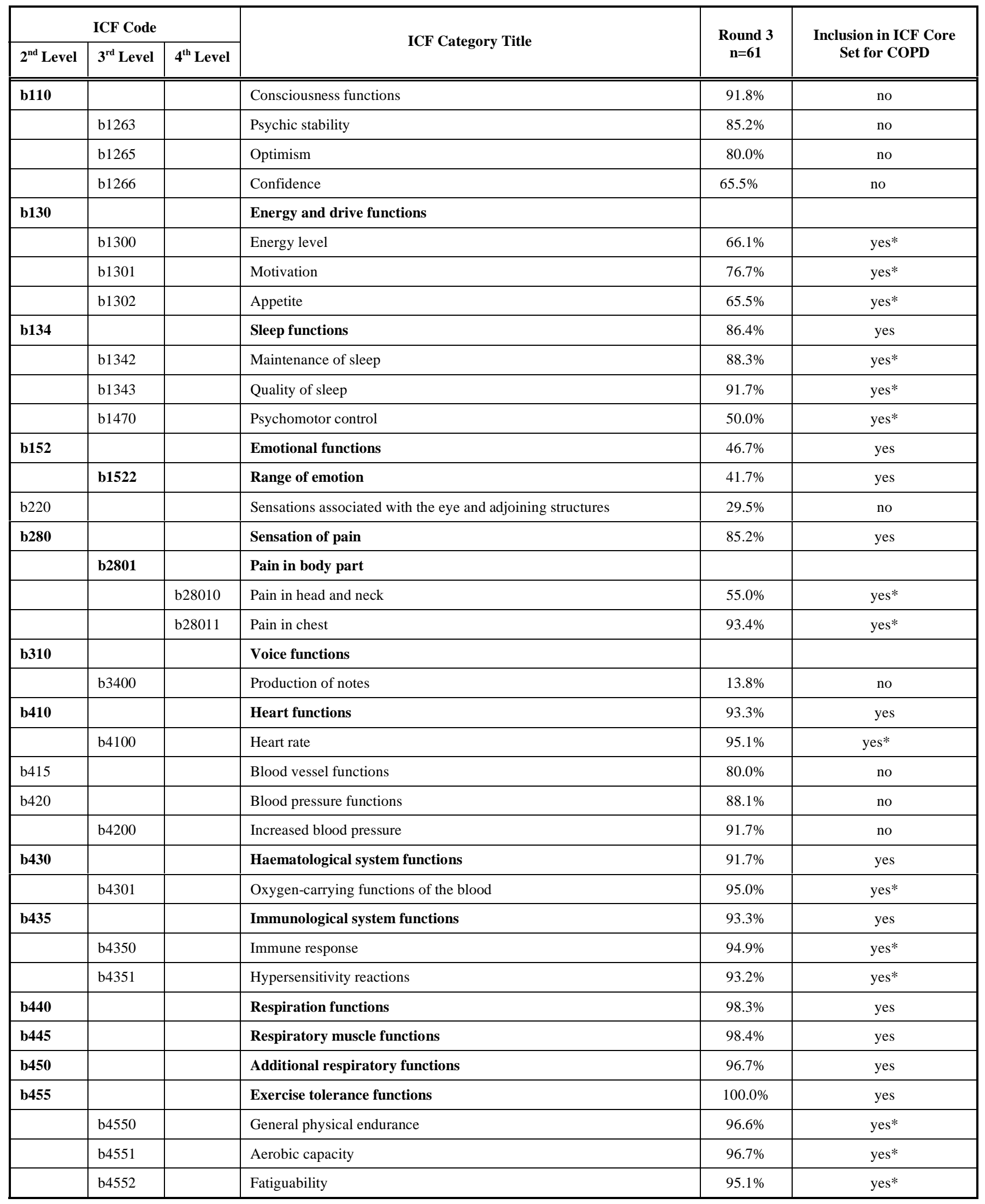




\begin{tabular}{|c|c|c|c|c|c|}
\hline \multicolumn{3}{|c|}{ ICF Code } & \multirow{2}{*}{ ICF Category Title } & \multirow{2}{*}{$\begin{array}{c}\text { Round } 3 \\
n=61\end{array}$} & \multirow{2}{*}{$\begin{array}{l}\text { Inclusion in ICF Core } \\
\text { Set for COPD }\end{array}$} \\
\hline $2^{\text {nd }}$ Level & $3^{\text {rd }}$ Level & $4^{\text {th }}$ Level & & & \\
\hline \multirow{2}{*}{ b460 } & b5104 & & Salivation & $36.1 \%$ & no \\
\hline & b5106 & & Regurgitation and vomiting & $66.1 \%$ & no \\
\hline b530 & & & Weight maintenance functions & $96.6 \%$ & yes \\
\hline b540 & & & General metabolic functions & $67.8 \%$ & no \\
\hline \multirow[t]{2}{*}{ b545 } & & & Water, mineral and electrolyte balance functions & $94.8 \%$ & no \\
\hline & b5500 & & Body temperature & $78.0 \%$ & no \\
\hline b730 & & & Muscle power functions & $70.0 \%$ & yes \\
\hline b735 & & & Muscle tone functions & $50.0 \%$ & no \\
\hline \multirow[t]{2}{*}{ b740 } & & & Muscle endurance functions & $62.1 \%$ & yes \\
\hline & b7651 & & Tremor & $62.7 \%$ & no \\
\hline \multirow[t]{2}{*}{ b780 } & & & Sensations related to muscles and movement functions & & \\
\hline & b7801 & & Sensation of muscle spasm & $59.3 \%$ & yes* \\
\hline $\mathrm{b} 810$ & & & Protective functions of the skin & $48.3 \%$ & no \\
\hline b820 & & & Repair functions of the skin & $46.7 \%$ & no \\
\hline
\end{tabular}

*ICF category is represented in the Comprehensive ICF Core Set for COPD by its corresponding higher-level (second or third level) category.

Since all PAH results in similar histological remodeling of pulmonary arteries with thickening of the intima, proliferation of the media and plexogenic lesions [26], the ICF category s410 Structure of cardiovascular system was included in the ICF Core Set for COPD [9]. In COPD supplemental oxygen and anticoagulation and not vasodilators remain to date the primary treatment for PAH [27]. Its potential reversibility might be explained by restoring blood vessel functions and blood pressure functions. Therefore it might be consequential to include this additional categories (b415 Blood vessel functions, b420 Blood pressure functions and b4200 Increased blood pressure) in the Comprehensive ICF Core Set for COPD.

The ICF category b545 Water, mineral and electrolyte balance functions is not included in the Comprehensive ICF

Table 3. Linking of the Experts Responses to the ICF Categories of the Component Body Structures: The Table Denotes the Percentage of Experts who Considered the Respective ICF Category as Relevant in the Third Delphi Round and the Correlation with the Comprehensive ICF Core Set for COPD. ICF Categories Included Comprehensive ICF Core Set for COPD are Printed in the Bold-Face Type

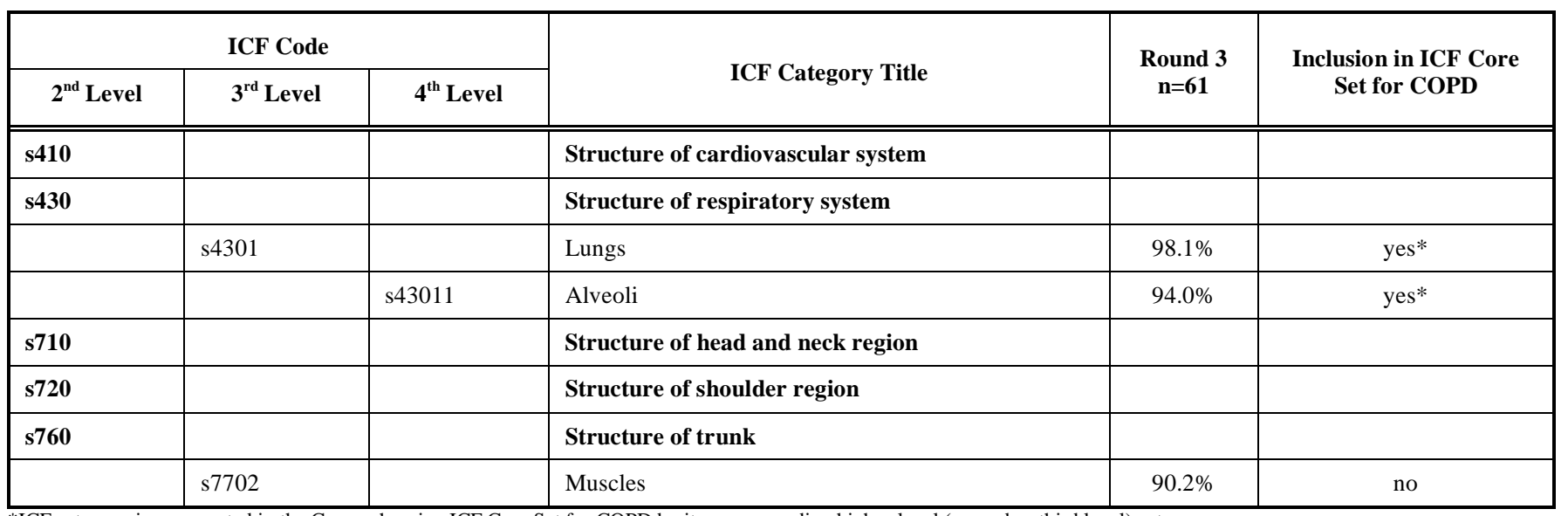


Table 4. Linking of the Experts Responses to the ICF Categories of the Component Activities and Participation: The Table Denotes the Percentage of Experts who Considered the Respective ICF Category as Relevant in the Third Delphi Round and the Correlation with the Comprehensive ICF Core Set for COPD. ICF Categories Included Comprehensive ICF Core Set for COPD are Printed in the Bold-Face Type

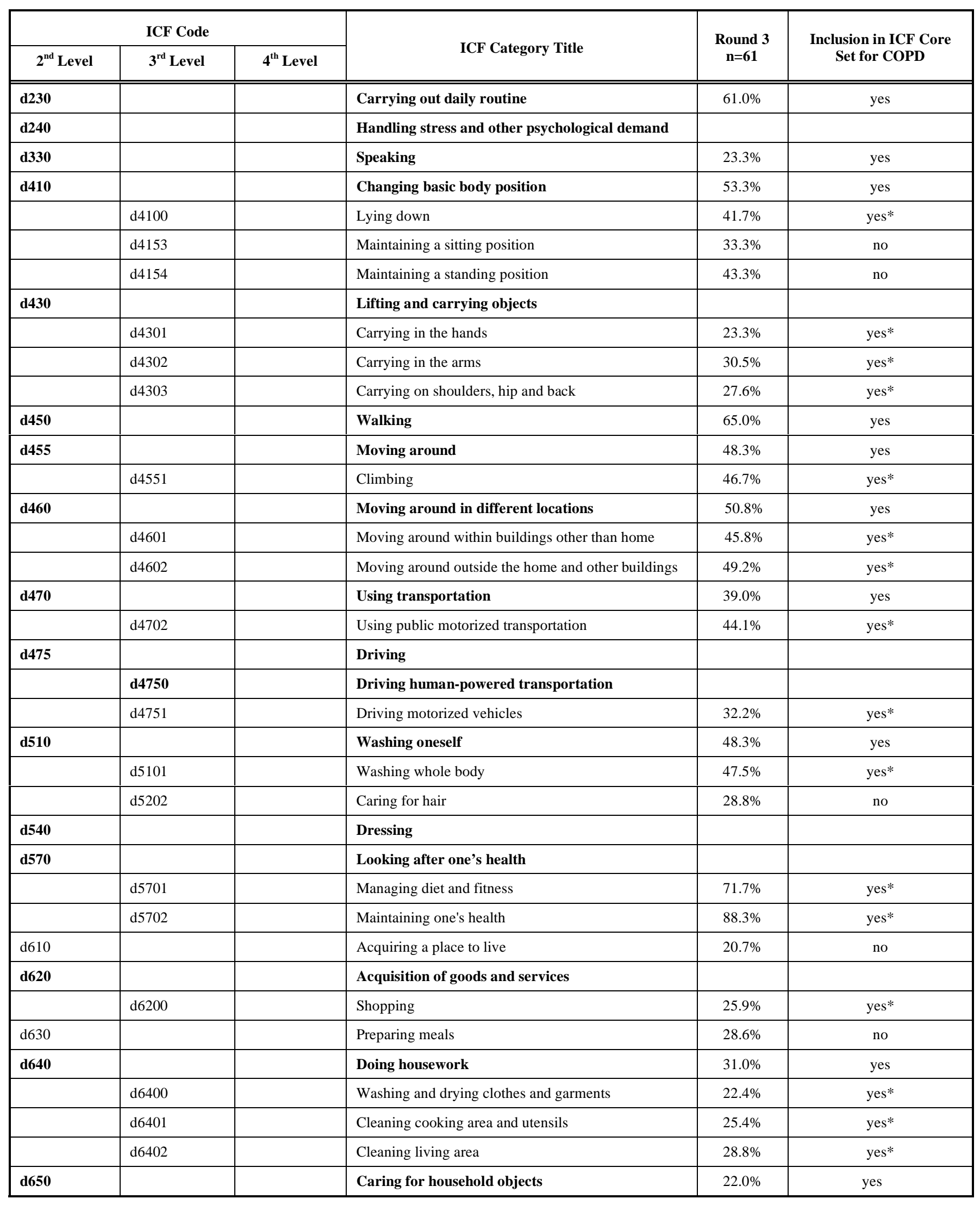




\begin{tabular}{|c|c|c|c|c|c|}
\hline \multicolumn{3}{|c|}{ ICF Code } & \multirow{2}{*}{ ICF Category Title } & \multirow{2}{*}{$\begin{array}{c}\text { Round } 3 \\
n=61\end{array}$} & \multirow{2}{*}{$\begin{array}{l}\text { Inclusion in ICF Core } \\
\text { Set for COPD }\end{array}$} \\
\hline $2^{\text {nd }}$ Level & $3^{\text {rd }}$ Level & $4^{\text {th }}$ Level & & & \\
\hline \multirow[t]{2}{*}{ d740 } & & & Formal relationships & $23.7 \%$ & no \\
\hline & $\mathrm{d} 7400$ & & Relating with persons in authority & $21.1 \%$ & no \\
\hline d760 & & & Family relationships & $37.3 \%$ & no \\
\hline \multirow[t]{2}{*}{ d770 } & & & Intimate relationships & & \\
\hline & d7702 & & Sexual relationships & $45.6 \%$ & yes* \\
\hline $\mathrm{d} 820$ & & & School education & $13.6 \%$ & no \\
\hline d845 & d8452 & & Terminating a job & $43.3 \%$ & yes* \\
\hline d850 & & & Remunerative employment & $27.1 \%$ & yes \\
\hline \multirow[t]{2}{*}{$\mathrm{d} 855$} & & & Non-remunerative employment & $15.3 \%$ & no \\
\hline & $\mathrm{d} 8700$ & & Personal economic resources & $21.1 \%$ & no \\
\hline \multirow[t]{3}{*}{ d910 } & & & Community life & & \\
\hline & d9100 & & Informal associations & $20.3 \%$ & yes* \\
\hline & d9101 & & Formal associations & $13.6 \%$ & yes* \\
\hline d920 & & & Recreation and leisure & $53.3 \%$ & yes \\
\hline
\end{tabular}

*ICF category is represented in the Comprehensive ICF Core Set for COPD by its corresponding higher-level (second or third level) category.

Core Sets for COPD, but was considered as a relevant problem treated by physicians in patients with COPD. Salt and water retention, reduced renal blood flow and diminished glomerular filtration rate as well as neurohumoralabnormalities [28, 29] can be found in COPD patients. Even though there is only few data available concerning the fluid homeostasis in patients with COPD only, not affected by cardiac co-morbitities e.g. heart failure. However, since sodium retention and resulting volume congestion often lead to massive edema, a common problem of patients with COPD, it may therefore be useful to integrate the ICF category b545 Water, mineral and electrolyte balance functions into the Comprehensive ICF Core Sets for COPD.

Seventy-eight percent of the experts regarded the ICF category b5500 Body temperature as a relevant aspect in patients with COPD, especially in association with acute exacerbations. Unfortunately, many definitions of exacerbations of COPD exists. The most widely used criteria include worsening of dyspnea and changes in sputum production, but not body temperature. Therefore, this category is not included in the Comprehensive ICF Core Set for COPD. However, acute exacerbations of COPD can be characterized by systemic clinical descriptors such as increased body temperature $[30,31]$. With regard to diagnostics of exacerbations, one could consider an inclusion of the ICF category b5500 Body temperature in the ICF Core Sets for COPD.

From the ICF component Body Structures, the category s7702 Muscles is not included in the Comprehensive ICF Core Set for COPD, but received an agreement of above $75 \%$. In fact, the ICF categories s710 Structure of head and neck region, s720 Structure of shoulder region and $s 760$ Structure of trunk, which are included in the Comprehensive Core Sets for COPD, also comprise muscles of the respective region. However, since muscle weakness in chronic COPD concerns respiratory muscles as well as limb muscles [32], one should consider whether it could be helpful to include the category s7702 Muscles which focuses on musculoskeletal structures related to movement.

A large number of the participants' responses were identified as Personal Factors. Personal factors are contextual factors that relate to the individual such as age, 
Table 5. Linking of the Experts Responses to the ICF Categories of the Component Environmental Factors: The Table Denotes the Percentage of Experts who Considered the Respective ICF Category as Relevant in the Third Delphi Round and the Correlation with the Comprehensive ICF Core Set for COPD. ICF Categories Included Comprehensive ICF Core Set for COPD are Printed in the Bold-Face Type

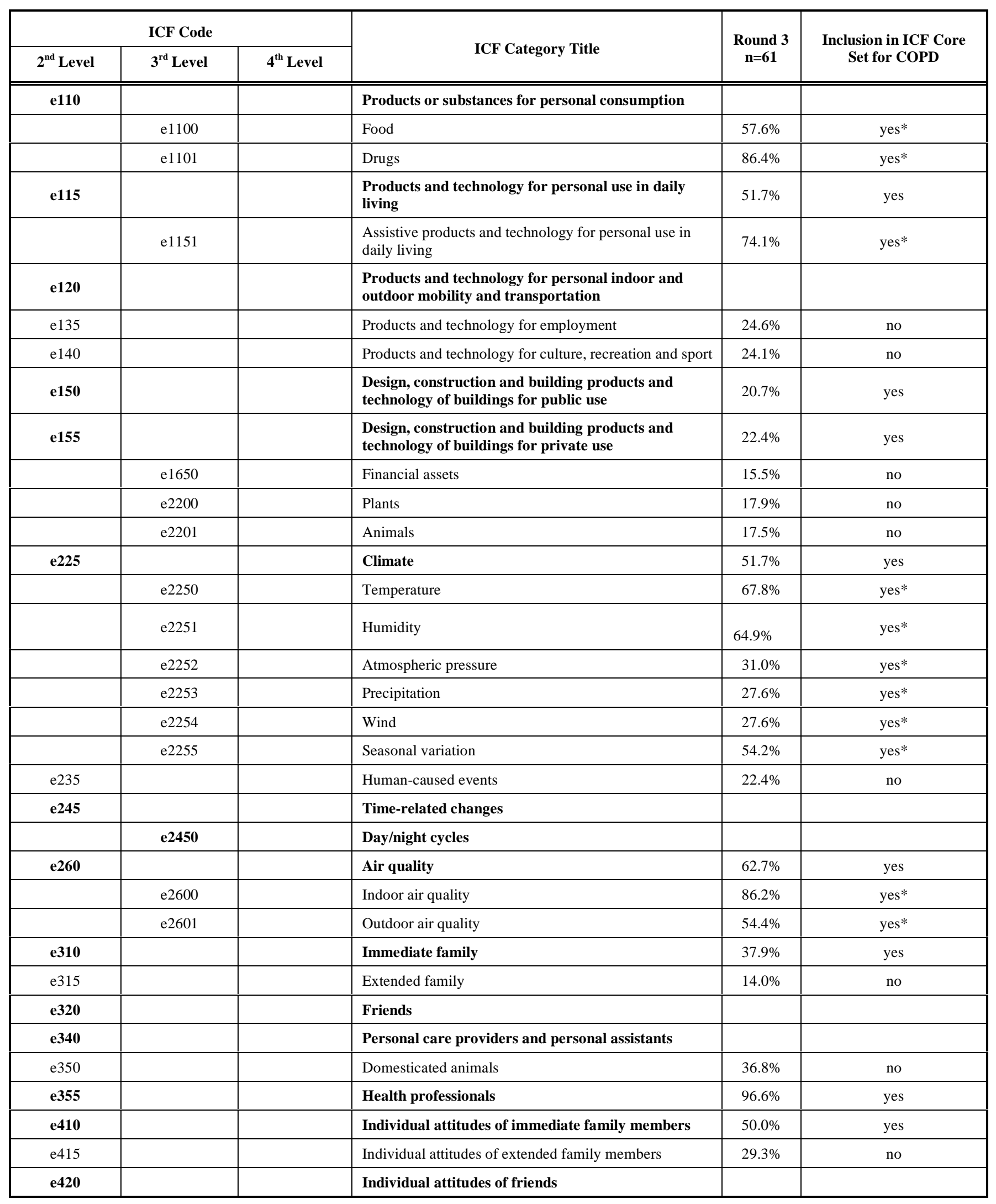




\begin{tabular}{|c|c|c|c|c|c|}
\hline \multicolumn{3}{|c|}{ ICF Code } & \multirow{2}{*}{ ICF Category Title } & \multirow{2}{*}{$\begin{array}{c}\text { Round } 3 \\
\mathrm{n}=61\end{array}$} & \multirow{2}{*}{$\begin{array}{l}\text { Inclusion in ICF Core } \\
\text { Set for COPD }\end{array}$} \\
\hline $2^{\text {nd }}$ Level & $3^{\text {rd }}$ Level & $4^{\text {th }}$ Level & & & \\
\hline e450 & & & Individual attitudes of health professionals & $89.7 \%$ & yes \\
\hline e460 & & & Societal attitudes & $33.9 \%$ & yes \\
\hline $\mathrm{e} 465$ & & & Social norms, practices and ideologies & $24.6 \%$ & no \\
\hline \multirow[t]{2}{*}{ e540 } & & & Transportation services, systems and policies & $27.6 \%$ & yes \\
\hline & e5502 & & Legal policies & $16.9 \%$ & no \\
\hline \multirow[t]{2}{*}{ e555 } & & & $\begin{array}{l}\text { Associations and organizational services, systems } \\
\text { and policies }\end{array}$ & & \\
\hline & e5550 & & Associations and organizational services & $50.8 \%$ & yes* \\
\hline \multirow[t]{2}{*}{ e570 } & & & Social security services, systems and policies & $51.7 \%$ & no \\
\hline & e5700 & & Social security services & $56.7 \%$ & no \\
\hline \multirow[t]{2}{*}{ e575 } & & & $\begin{array}{l}\text { General social support services, systems and } \\
\text { policies }\end{array}$ & $61.7 \%$ & yes \\
\hline & e5750 & & General social support services & $62.7 \%$ & yes* \\
\hline \multirow[t]{4}{*}{ e580 } & & & Health services, systems and policies & & \\
\hline & $\mathrm{e} 5800$ & & Health services & $85.0 \%$ & yes* \\
\hline & e5801 & & Health systems & $76.7 \%$ & yes* \\
\hline & e5802 & & Health policies & $69.0 \%$ & yes* \\
\hline e585 & & & $\begin{array}{l}\text { Education and training services, systems and } \\
\text { policies }\end{array}$ & & \\
\hline e590 & & & $\begin{array}{l}\text { Labour and employment services, systems and } \\
\text { policies }\end{array}$ & & \\
\hline
\end{tabular}

*ICF category is represented in the Comprehensive ICF Core Set for COPD by its corresponding higher-level (second or third level) category.

gender, education, coping styles, overall behaviour pattern, character style and individual psychological assets [8]. However, they are not yet classified in the ICF. There is a consensus in literature that personal factors like coping styles, self-efficacy, and optimistic attitude, contribute to medical treatment and quality of life in patients with COPD $[33,34]$. It may therefore be helpful to provide a classification of the personal factors in the future to enable a systematic identification of all personal factors influencing the functioning of a certain person.

The Delphi technique was an appropriate method for this study objective. In contrast to the mean attrition rates of 50\% or higher from round to round reported in literature, response rates between the rounds ranging from 77 to $94 \%$ were achieved in our study [35, 36].

However, there are some limitations regarding the external validity of this study. First, a small proportion of the physicians who were initially contacted, finally participated in the study. Thus, a selection bias cannot be excluded. Moreover, participants provided a self-rating of their experience with COPD treatment. Although they reported a high median level of experience, objective ratings may have differed from the self-reports. In addition, cultural differences may exist: an expert on COPD in a developing country such as Sudan is expected to have a different level of expertise than a physician from an industrialized country. The overall response rate in this study is similar with studies using comparable strategies to recruit physicians worldwide for a Delphi survey on the ICF [37]. Reasons for not responding to our invitation could have been a lack of interest in rehabilitation issues among the physicians, a low knowledge of the ICF and restricted time resources. However, we were not able to systematically collect information on the reasons for non-responding.

Although the authors were successful in recruiting 76 physicians from 44 countries, the sample consists predominantly of physicians from Europe. Especially from the African, South East Asian and Eastern Mediterranean world region, only few physicians could be recruited. Language barriers as well as a lack of internet access could have influenced the participation, as the Delphi survey was exclusively conducted in English language by electronic mail. Therefore, this sample does not represent the whole spectrum of physicians experienced in the treatment of COPD patients worldwide. In addition, the unequal contribution of countries may also have affected the study results since patients symptoms and functional limitations, and physicians treatment goals may vary between the different cultures. Further validation studies including physicians from countries not sufficiently represented in this study should be conducted.

Another limitation refers to the $75 \%$ definition of level of consensus. This level of consensus is within the range of $51 \%$ to $80 \%$ agreement recommended in the literature [22] and its selection was based on the experiences with the development of ICF Core Sets for chronic conditions [10]. 
However, a modification of the level of consensus would have affected the results.

\section{CONCLUSION}

Although minor shortcomings of the current version of the Comprehensive ICF Core Set for COPD concerning the representation of several body functions and the personal factors from the physicians' perspective could be detected in this study, the Comprehensive ICF Core Set for COPD can be applied as a useful tool in clinical practice to enhance communication within multi-professional teams by referring to the common framework of the ICF model [8]. Based on the Comprehensive ICF Core Set for COPD, the impairments in body functions and structures, limitations in activities, restrictions in participation and the influential environmental factors of a determined patient can be described and the impact of COPD can be measured in a standardized way. A functioning profile can be created and used as a reference for follow-up. Since the treatment of COPD also requires a coordinated longitudinal care involving several health professions, an approach that structures the management among the different health professionals involved is needed. The Rehab-CYCLE is a problem solving approach for ICF-based rehabilitation management and facilitates goal setting, assignment of intervention targets to specific interventions and responsible health professionals and evaluation of goal achievement $[38,39]$. The Comprehensive ICF Core Set for COPD can be integrated in the Rehab-CYCLE and provide a useful tool for rehabilitation management.

Further research is necessary regarding the feasibility of the Comprehensive ICF Core Set for COPD in clinical practice. In addition, results of ongoing validation projects will further elucidate the validity of the Comprehensive ICF Core Set for COPD from the perspective of different health professions. The findings of all validation studies could be the basis for a revision and improvement of the Comprehensive ICF Core Set for COPD.

\section{ACKNOWLEDGEMENTS}

We thank the participants of the Delphi exercise for their valuable contribution and their time in responding to the demanding questionnaires. In addition, we are grateful to Edda Amann for performing the linking of the participants' responses to the ICF.

\section{DISCLOSURE}

The methodology used to collect the data presented in this paper is very similar to that of a paper previously published in Psychology and Health, Volume 23, Number 6, August 2008, pp. 639-659(21): Thus, there is some overlapping in the information contained in both papers.

\section{CONFLICT OF INTEREST}

The authors confirm that this article content has no conflict of interest.

\section{REFERENCES}

[1] Guerra S. Overlap of asthma and chronic obstructive pulmonary disease. Curr Opin Pulm Med 2005; 11: 7-13.
[2] Fabbri LM, Hurd SS. Global Strategy for the Diagnosis, Management and Prevention of COPD: 2003 update. Eur Respir J 2003; 22: 1-2.

[3] Global Strategy for the Diagnosis, Management and Prevention of COPD. Global Initiative for Chronic Obstructive Lung Disease (GOLD) 2010. Available from: http://www.goldcopd.org/

[4] Álvarez-Gutiérrez FJ, Miravitlles M, Calle M, et al. Impact of Chronic Obstructive Pulmonary Disease on Activities of Daily Living: Results of the Multicenter EIME Study. Arch Bronconeumol 2007; 43: 64-72.

[5] Ramsey SD, Sullivan SD. The burden of illness and economic evaluation for COPD. Eur Respir J Suppl 2003; 41: 29s-35s.

[6] Kunik ME, Roundy K, Veazey C, et al. Surprisingly high prevalence of anxiety and depression in chronic breathing disorders. Chest 2005; 127: 1205-11.

[7] Stucki G, Ewert T, Cieza A. Value and application of the ICF in rehabilitation medicine. Disabil Rehabil 2003; 25: 628-34.

[8] World Health Organization. ICF - International Classification of Functioning, Disability and Health. Geneva: World Health Organization 2001

[9] Stucki A, Stoll T, Cieza A, et al. ICF Core Sets for obstructive pulmonary diseases. J Rehabil Med 2004; 44: 114-20.

[10] Cieza A, Ewert T, Ustün B, Chatterji S, Kostanjsek N, Stucki G. Development of ICF Core Sets for patients with chronic conditions. J Rehabil Med 2004; 44: 9-11.

[11] Brockow T, Cieza A, Kuhlow H, et al. Identifying the concepts contained in outcome measures of clinical trials on musculoskeletal disorders and chronic widespread pain using the International Classification of Functioning, Disability and Health as a reference. J Rehabil Med 2004; 44: 30-6.

[12] Ewert T, Fuessl M, Cieza A, et al. Identification of the most common patient problems in patients with chronic conditions using the ICF checklist. J Rehabil Med 2004; 44: 22-9.

[13] Weigl M, Cieza A, Andersen C, Kollerits B, Amann E, Stucki G. Identification of relevant ICF categories in patients with chronic health condictions: a Delphi exercise. J Rehabil Med 2004; 44: 1221.

[14] Linstone HA, Turoff M. The Delphi technique: techniques and applications. London: Addison Wesley 1975.

[15] McKenna HP. The Delphi technique: a worthwhile approach for nursing? J Adv Nurs 1994; 19: 1221-5.

[16] Jones J, Hunter D. Consensus methods for medical and health services research. BMJ 1995; 311: 376-80.

[17] Polit DF, Hungler BP. Essentials of Nursing Research: Methods, Appraisal and Utilisation. New York: Lippincott 1997.

[18] Cieza A, Brockow T, Ewert $\mathrm{T}$, et al. Linking health-status measurements to the international classification of functioning, disability and health. J Rehabil Med 2002; 34: 205-10.

[19] Cohen J. A coefficient of agreement for nominal scales. Educ Psychol Meas 1960; 20: 37-46.

[20] Vierkant RA. A SAS macro for calculating bootstrapped confidence intervals about a kappa coefficient. Available at: http://www2.sas.com/proceedings/sugi22/STATS/PAPER295.PDF [Accessed: June 23 2011].

[21] World Health Organization. Statistical classification of diseases and related health problems. $10^{\text {th }}$ Revision. v.3 Tabular List. Geneva, Switzerland: WHO 1994.

[22] Hasson F, Keeney S, Mc Kenna H. Research guidelines for the Delphi survey technique. J Adv Nurs 2000; 32: 1008-15.

[23] Scala R, Naldi M, Archinucci I, Coniglio G, Nava S. Noninvasive positive pressure ventilation in patients with acute exacerbations of COPD and varying levels of consciousness. Chest 2005; 128: 165766.

[24] Nejtek VA, Brown ES, Khan DA, Moore JJ, Van Wagner J, Perantie DC. Prevalence of mood disorders and relationship to asthma severity in patients at an inner-city asthma clinic. Ann Allergy Asthma Immunol 2001; 87: 129-33.

[25] Yohannes AM, Roomi J, Baldwin RC, Connolly MJ. Depression in elderly outpatients with disabling chronic obstructive pulmonary disease. Age Ageing 1998; 27: 155-60.

[26] Nicod LP. Pulmonary hypertension. Swiss Med Wkly 2003; 133(78):103-10.

[27] Chaouat A, Naeije R, Weitzenblum E. Pulmonary hypertension in COPD. Eur Respir J 2008; 32(5): 1371-85.

[28] De Leeuw PW, Dees A. Fluid homeostasis in chronic obstructive lung disease. Eur Respir J Suppl 2003; 46: 33s-40s. 
[29] Anand IS, Chandrashekhar Y, Ferrari R, et al. Pathogenesis of congestive state in chronic obstructive pulmonary disease. Studies of body water and sodium, renal function, hemodynamics, and plasma hormones during edema and after recovery. Circulation 1992; 86: 12-21.

[30] Rodriguez-Roisin R. Toward a consensus definition for COPD exacerbations. Chest 2000; 117(5 Suppl 2): 398s-401s.

[31] Lieberman D, Shmarkov O, Gelfer Y, Varshavsky R, Lieberman DV. Prevalence and clinical significance of fever in acute exacerbations of chronic obstructive pulmonary disease. Eur J Clin Microbiol Infect Dis 2003; 22: 75-8.

[32] MacIntyre NR. Muscle dysfunction associated with chronic obstructive pulmonary disease. Respir Care 2006; 51(8): 840-7.

[33] Kubzansky LD, Wright RJ, Cohen S, Weiss S, Rosner B, Sparrow D. Breathing easy: a prospective study of optimism and pulmonary function in the normative aging study. Ann Behav Med 2002; 24: 345-53.

[34] Smith L, Bosnic-Antisevich SZ, Mitchell B, Saini B, Krass I, Armour C. Treating asthma with a self-management model of illness behaviour in an Australian community pharmacy setting. Soc Sci Med 2007; 67(7): 1501-11.

[35] Geschka H. Delphi. In: Longterm prognosis. Bruckmann G, Ed. Würzburg/Wien: Heibert 1977.

[36] Race KEH, Planek TW. Modified scree test. Further considerations on its application to Delphi study data. Eval Rev 1992; 16: 171-83.

[37] Lemberg I, Kirchberger I, Stucki G, Cieza A. The ICF Core Set for stroke from the perspective of physicians: a worldwide validation study using the Delphi technique. Eur J Phys Rehabil Med 2010; 46: 377-88.

[38] Steiner WA, Ryser L, Huber E, Uebelhart D, Aeschlimann A, Stucki G. Use of the ICF model as a clinical problem-solving tool in physical therapy and rehabilitation medicine. Phys Ther 2002; 82: 1098-107.

[39] Rauch A, Cieza A, Stucki G. How to apply the International Classification of Functioning, Disability and Health (ICF) for rehabilitation management in clinical practice. Eur J Phys Rehabil Med 2008; 44: 329-42.

(C) Jobst et al.; Licensee Bentham Open.

This is an open access article licensed under the terms of the Creative Commons Attribution Non-Commercial License (http://creativecommons.org/licenses/by-nc/3.0/) which permits unrestricted, non-commercial use, distribution and reproduction in any medium, provided the work is properly cited. 